\title{
Vorwort zur I. Auflage.
}

Während meiner Vorlesungen über Verbandlehre mit Besprechung der Luxationen und Fracturen ist an mich zu wiederholten Malen von Zuhörern die Frage gerichtet worden, ob ich ihnen nicht ein praktisches Lehrbuch über Verrenkungen und Brüche zum Studium empfehlen könnte. Meine Antwort hierauf konnte nur die sein, dass ein dem geforderten $Z$ wecke entsprechendes Buch nicht existiere und dass dazu nur die Lehrbücher über Chirurgie überhaupt anzuwenden seien. Das umfangreiche Werk Hamilton's über Knochenbrüche und Verren-

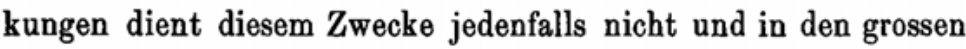
chirurgischen Sammel-Werken ist das Material zu zerstreut abgehandelt. Um hier nun helfend einzugreifen, habe ich es versucht, gleichsam eine Grammatik der Luxationen für Studierende und besonders für praktische Aerzte zu schreiben. Ich that dies um so lieber, als ich mich während meiner elfjährigen chirurgischen Thätigkeit stets mit besonderer Neigung mit Verrenkungen und Brüchen beschäftigt habe, wozu mir eine sechsjährige Assistenten-Zeit an der hiesigen königlichen chirurgischen Klinik reichliche Gelegenheit bot, sodass ich im Stande bin eigenes Urteil und manche selbst gemachte Erfahrung für die Arbeit zu verwerten. Ich möchte, dass in derselben nichts 
Wissenswertes fehle, und gebe im Allgemeinen nur zur Zeit Feststehendes. Das Buch soll aber im eigentlichen Sinne des Wortes auch ein Hand- und Nachschlagebuch für den praktischen Arzt sein, das ihm ermöglicht die besprochenen Verletzungen lege artis zu erkennen und $z u$ behandeln, ohne in den Lehrbüchern sich erst das unbedingt Notwendige heraussuchen zu müssen. Grade die in Rede stehenden Verletzungen sind von so eminent praktischer Bedeutung und ein Versehen in der Diagnose oder Behandlung von oft zeitlebens üblen Folgen, so dass die Abfassung eines kurzen aber alles Wesentliche umfassenden Lehrbuches gerade für den Arzt gewiss gerechtfertigt erscheint. Wenn es mir mit den folgenden Blättern gelungen ist für Studierende, Aerzte und Patienten etwas Nützliches geschaffen $z u$ haben, so ist der Zweck reichlich erfüllt.

\section{Vorwort zur II. Auflage.}

In der vorliegenden II. Auflage des Compendiums habe ich es mir vor Allem angelegen sein lassen den berechtigten Wtinschen der Kritiken der I. Auflage nachzukommen. Der allgemeine Teil ist erweitert und es sind Zeichnungen hinzugefügt. In der Beschreibung der einzelnen Verrenkungen habe ich im Wesentlichen nichts geändert, da ich den Charakter eines Compendiums beibehalten wollte. Ich bemerke jedoch ausdrücklich, dass sich beide Bücher - über Luxationen und Fracturen - gegenseitig ergänzen sollen. 